\title{
GIS Approach to Determine Suitability of Trees for Afforestation
}

\author{
Mrs. Vidya Zope ${ }^{1}$, Nihar Kalsekar ${ }^{2}$, Pradyot Chhatwani ${ }^{3}$, Vaibhav Mane ${ }^{4}$ \\ ${ }^{1}$ Assistant Professor, Department of Computer Engineering, V.E.S. Institute of Technology, Chembur, Mumbai, India \\ ${ }^{2,3,4}$ Undergraduate Student, Department of Computer Engineering, V.E.S. Institute of Technology, Chembur, Mumbai, India \\ Correspondence should be addressed to Mrs.Vidya Zope; vidya.zope@ves.ac.in
}

Copyright (C) 2021 Made Mrs. Vidya Zope et al. This is an open access article distributed under the Creative Commons Attribution License, which permits unrestricted use, distribution, and reproduction in any medium, provided the original work is properly cited.

\begin{abstract}
- 9.4 million trees across forest areas in India have been lost to development projects over the period of past 4 years (2015-16 to 2018-19). This is according to the Union ministry of environment, forests and climate change (MoEFCC). Afforestation refers to the effort to plant trees in barren lands to create a forest. Planting trees, sowing seeds in a barren land so as to create a forest. It is very vital as it helps to keep in check the over usage of natural resources by providing an alternative source. Planting trees is always beneficial to the environment regardless of the habitat.
\end{abstract}

KEYWORDS- Geographical Information System, Weighted Sum, Rasters, Landscape Model.

\section{INTRODUCTION}

Controlling of the carbon outflow frequently is a difficult undertaking for a nation like India. Much of the areas are covered by large industries and power plants. Creating Infrastructure, Industries (Steel, Power, Engineering, etc.), Mining (Coal, Minerals, Metals, etc.), Oil and Gas exploration, Thermal Power plants, etc are some of the reasons why major deforestation has occurred in India. Conversion of forested land to non -forested land by humans is referred to as Deforestation. It is one of the most challenging problems India is facing. Deforestation happens when a land overwhelmed by normally happening trees is changed over to offer particular types of assistance because of human interest. The erratic chopping down of trees has brought about the worldwide forest cover diminishing by $3.16 \%$ from 1990 to 2015 . There are significant amounts of regions in India which have seen a decrease in forest cover, even though the country has seen an increment in total forest cover of ca. $1 \%$. Shifting cultivation, rotational felling, other biotic pressures, diversion of forest lands for developmental activities are some of the main reasons for deforestation in the country. Continuous cutting of trees has severely impacted the microclimatic conditions, hydrological cycle, soil quality, etc. of the country, making the country vulnerable to an eventful happening. ${ }^{[1]}$

\section{RELATED WORK}

\section{A. Remote Sensing}

The remote sensor collects data by detecting the energy that is reflected from Earth. ${ }^{[2]}$ These sensors can be on satellites or can be mounted on an aircraft. These sensors can be either active or passive. Passive sensors respond to external stimuli. Natural energy is recorded that is reflected or emitted from the Earth's surface. Reflected sunlight is the most common source of detected radiation by passive sensors.

\section{B. Geographical Information System}

Geographic information system is a system designed and is used to store, manage, manipulate, capture, analyse, and present all types of geographical data. The word Geography is the critical element - it means that some portion of the data is spatial. In other words, data that is in some way referring to locations on the earth. ${ }^{[3]}$ Along with spatial data, tabular data widely known as attribute data, which can be defined as additional information about each of the spatial features. For example, the actual location of the monument is the spatial data. Additional data such as the monument name, year of creation, tourist data would make up the attribute data.

\section{Forest Assessment Using GIS}

Humans have always considered forests to be the best renewable source due to their role in preserving an environment that is ideal for life. ${ }^{[4]}$ Management of forests is a discipline that has been embraced by the greater part of the nations over the world. Financial matters managing the estimation of forest development, volume, timber harvest, utilization and benefits. GIS technology has been responsible for the decision-making processes for a few years now. GIS with other technologies has helped environmentalists to keep clear records regarding forests and make decisions based on the data obtained. GIS is becoming popular due to its benefits on the environment.

\section{APPROACH}

Here, we will be giving the details about our approach regarding all the steps of this project. Right from data collection and generation to landscape modelling, every part is covered in this section.

\section{A. Dataset}

The whole of Indian Subcontinent was taken into consideration during the conduct of this research. We have prepared a dataset of all the required parameters by collecting the rasters of the same. ${ }^{[5]}$ Some images of the Rasters have been shown below from figure number 1 to 5 , which are taken from various sources. 


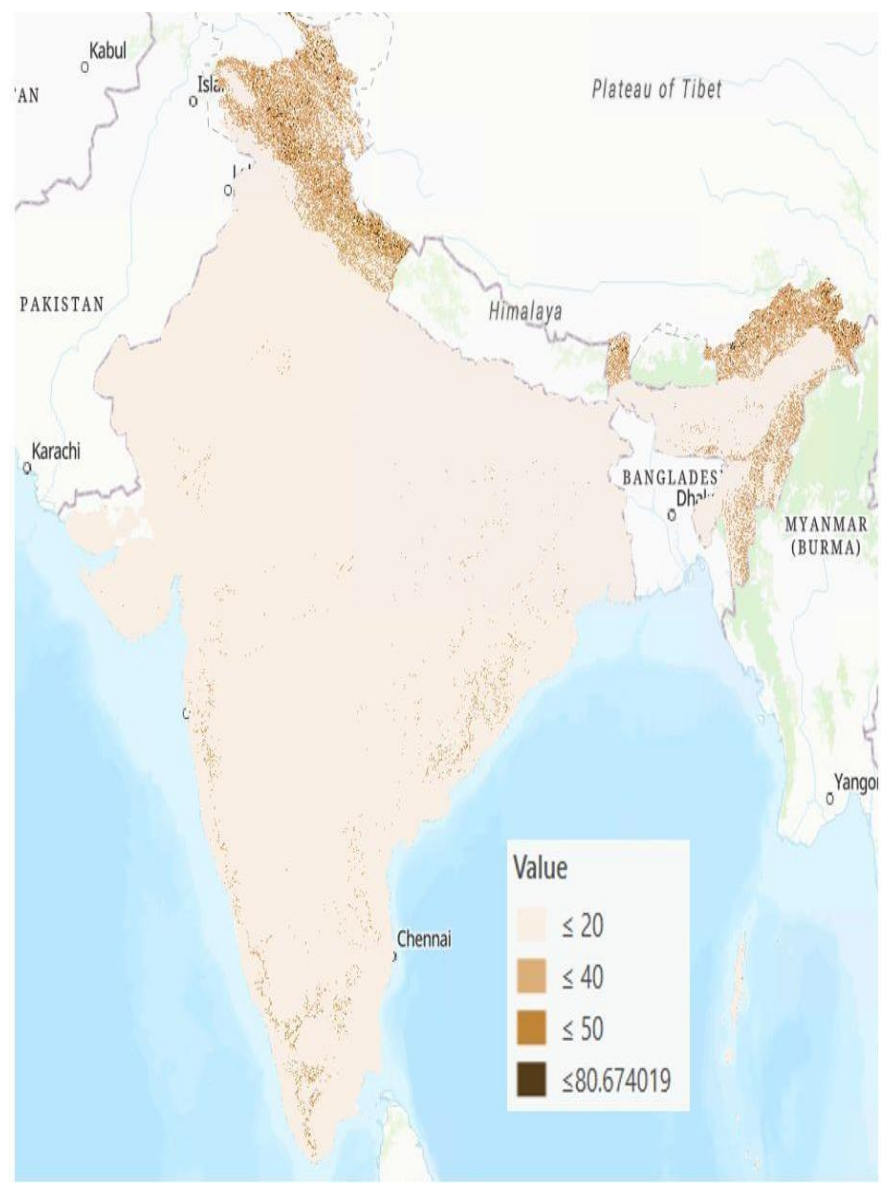

Fig. 1: Slope map

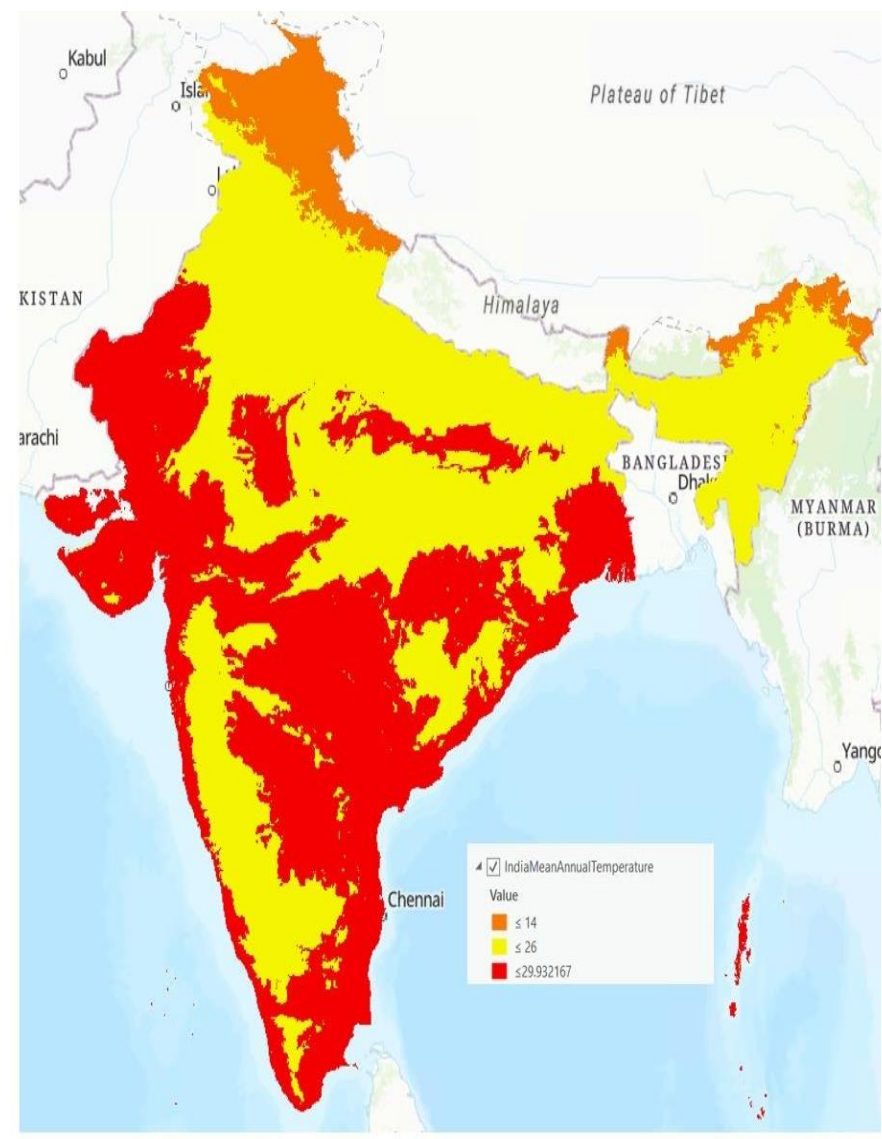

Fig. 2: Temperature Map

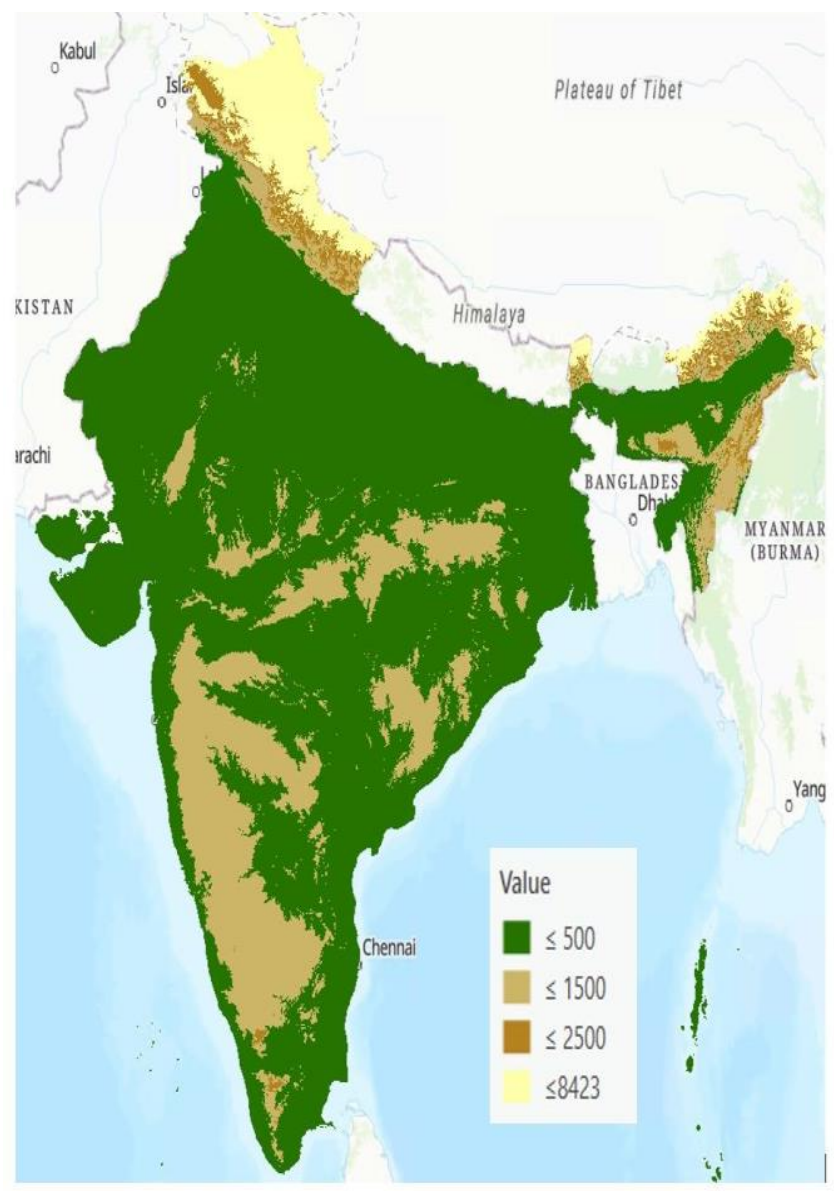

Fig. 3: Elevation map

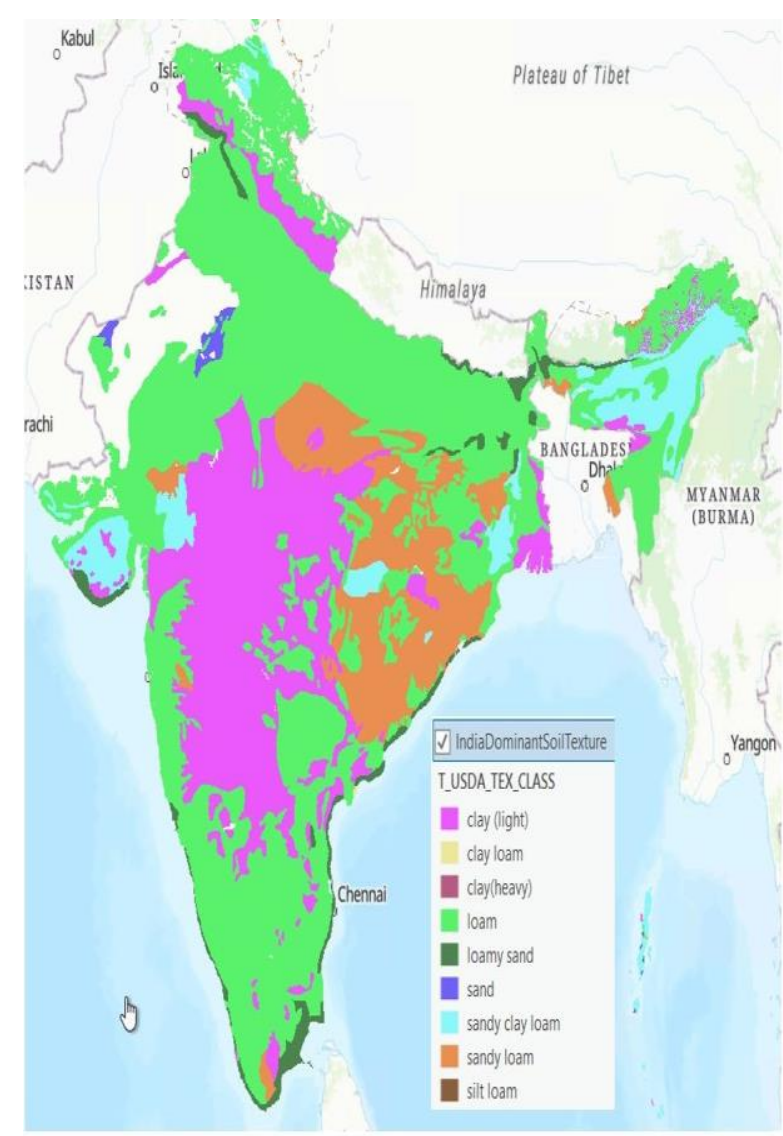

Fig. 4: Soil Texture Map 


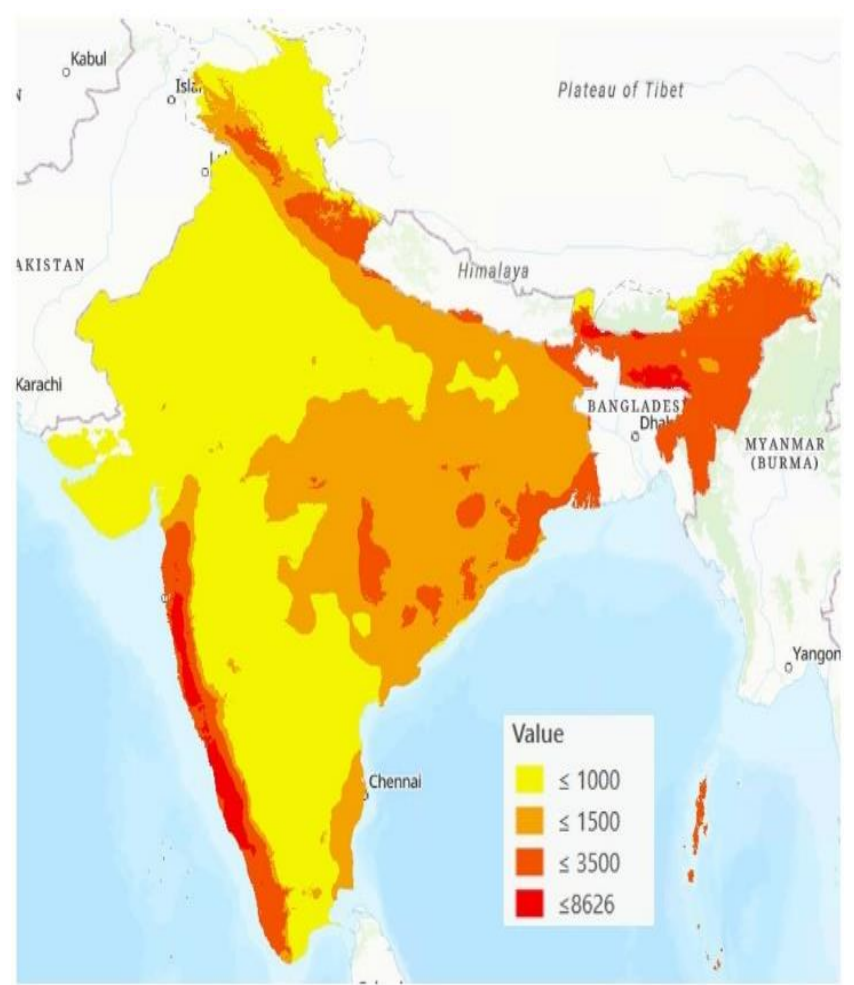

Fig. 5: Annual Rainfall Map

\section{B. Quantification Of Data}

The input parameters taken into consideration were temperature, elevation, slope, soil texture and the rainfall. ${ }^{[6]}$ These were divided into several categories as presented in the Table 1, Table 2 and Table 3. For every one of the classes, an integer value was defined. This value represents the suitability of a particular tree species concerning a certain parameter. ${ }^{[7]}$

Table 1: Sal Tree Classification Values

\begin{tabular}{|c|c|c|}
\hline & Range & Value \\
\hline \multirow{4}{*}{ Rainfall } & $<1500$ & 2 \\
\hline & $1000-1500$ & 5 \\
\hline & $1500-3500$ & 9 \\
\hline & $>3500$ & 4 \\
\hline \multirow{4}{*}{ Slope } & $<20$ & 9 \\
\hline & $20-40$ & 7 \\
\hline & $40-50$ & 3 \\
\hline & $>50$ & 1 \\
\hline \multirow{4}{*}{ Elevation } & $<500$ & 2 \\
\hline & $500-1500$ & 5 \\
\hline & $1500-2500$ & 9 \\
\hline & $>2500$ & 4 \\
\hline & $<28$ & 5 \\
\hline & $28-34$ & 9 \\
\hline & $>34$ & 4 \\
\hline \multirow{2}{*}{ Soil Texture } & Loamy Soil & 9 \\
\hline & Clay soil & 9 \\
\hline
\end{tabular}

\begin{tabular}{|l|l|l|}
\hline & Sandy soil & 9 \\
\cline { 2 - 3 } & Clay Loam & 4 \\
\hline
\end{tabular}

Table 2: Gulmohar Tree Classification Values

\begin{tabular}{|c|c|c|}
\hline & Range & Value \\
\hline \multirow{3}{*}{ Rainfall } & $<700$ & 2 \\
\hline & $700-1000$ & 7 \\
\hline & $>3500$ & 9 \\
\hline \multirow{4}{*}{ Slope } & $<20$ & 9 \\
\hline & $20-40$ & 7 \\
\hline & $40-50$ & 3 \\
\hline & $>50$ & 1 \\
\hline \multirow{4}{*}{ Elevation } & $<1000$ & 7 \\
\hline & $1000-2000$ & 9 \\
\hline & $2000-2500$ & 5 \\
\hline & $>2500$ & 4 \\
\hline \multirow{3}{*}{ Temperature $\left({ }^{\circ} \mathrm{C}\right)$} & $<14$ & 5 \\
\hline & $14-26$ & 9 \\
\hline & $>26$ & 4 \\
\hline \multirow{4}{*}{ Soil Texture } & Loamy Soil & 5 \\
\hline & Clay soil & 9 \\
\hline & Sandy soil & 7 \\
\hline & Clay Loam & 3 \\
\hline
\end{tabular}

Table 3: Arjuna Tree Classification Values

\begin{tabular}{|c|c|c|}
\hline & Range & Value \\
\hline \multirow{4}{*}{ Rainfall } & $<750$ & 2 \\
\hline & $750-1000$ & 5 \\
\hline & $1000-2000$ & 9 \\
\hline & $>2000$ & 4 \\
\hline \multirow{4}{*}{ Slope } & $<20$ & 9 \\
\hline & $20-40$ & 7 \\
\hline & $40-50$ & 3 \\
\hline & $>50$ & 1 \\
\hline \multirow{7}{*}{ Elevation } & $<500$ & 2 \\
\hline & $500-1200$ & 9 \\
\hline & $1200-2000$ & 7 \\
\hline & $>2000$ & 4 \\
\hline & $<5$ & 1 \\
\hline & $5-20$ & 3 \\
\hline & $>20$ & 9 \\
\hline \multirow{4}{*}{ Soil Texture } & Loamy Soil & 5 \\
\hline & Clay soil & 6 \\
\hline & Sandy soil & 8 \\
\hline & Clay Loam & 9 \\
\hline
\end{tabular}




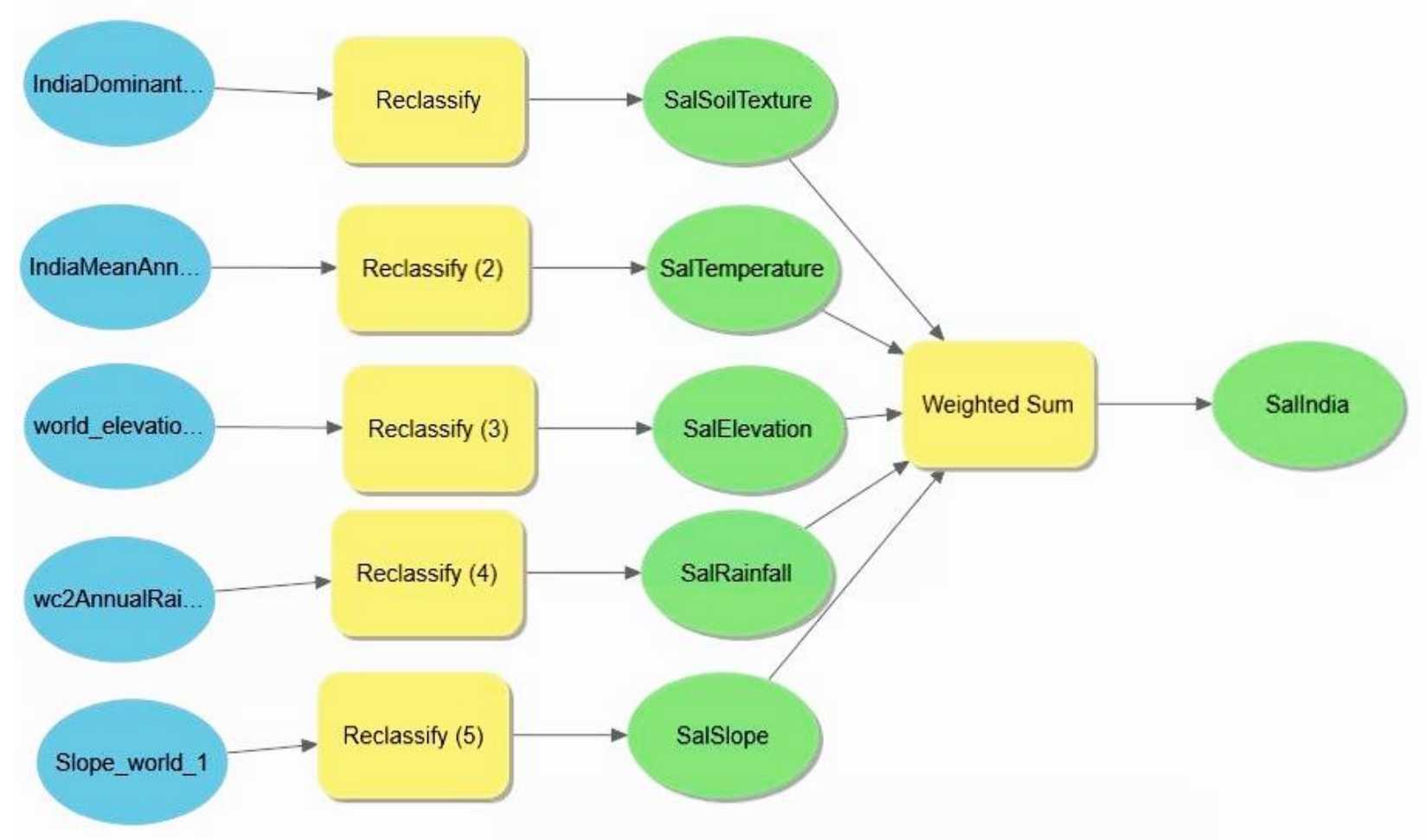

Fig. 6: Model Diagram

The diagram in the Fig. 6 shows the model created for the suitability classification of Sal Tree in the Indian Subcontinent. In this model:

- The Yellow Rectangular boxes represent geoprocessing tools used i.e. Reclassify and Weighted Overlay.

- Blue Ovals represents input raster

- Green Ovals represents processed rasters.

Here each raster obtained as explained above is taken as inputs and sent into a reclassifier to give rasters as per the classification given in the above tables. These reclassified rasters are then overlapped according to the value from the raster and the weight of the raster. This process is carried out at a pixel level and output gives the desired raster.

In the above model weights of the raster layers are taken as represented in Table 4.

Table 4: Layers and Weights

\begin{tabular}{|c|c|}
\hline Layer & Weight \\
\hline Rainfall & 0.22 \\
\hline Soil Texture & 0.22 \\
\hline Temperature & 0.22 \\
\hline Slope & 0.17 \\
\hline Elevation & 0.17 \\
\hline
\end{tabular}

\section{Algorithm Implementation}

Designing plan choices frequently require the generation, correlation and comparison of design alternatives in an environment of multiple plan models. To help in such dynamic, designers go to numerical formalisms to help with positioning the other options. A famous way to rank alternatives against a bunch of $\mathrm{n}$ criteria is the weighted sum method. The weighted sum method is very popular due to its ease of use and its compelling form. It commonly takes form

$$
R_{j}=\sum_{i=1}^{n} w_{i} q_{i j}
$$

Weighted sum formula

In our project, the final formula can be represented as:

(Rainfall value*weight $)+($ Soil Texture*weight $)+$ $($ Temperature value*weight $)+($ Slope value*weight $)+$ (Elevation value*weight)

Here the weight refers to the weights of each parameter as described in the above table.

\section{Results And Discussion}

The results of this research and the method used enables us to prepare a suitability map of each of the three species of plants namely Sal, Gulmohar and Arjuna tree shown in Fig. 7, Fig. 8 and Fig. 9 respectively, which categorizes the region based on the suitability where the tree can grow in the Indian Subcontinent. A detailed description of each species and its corresponding map is given below. 


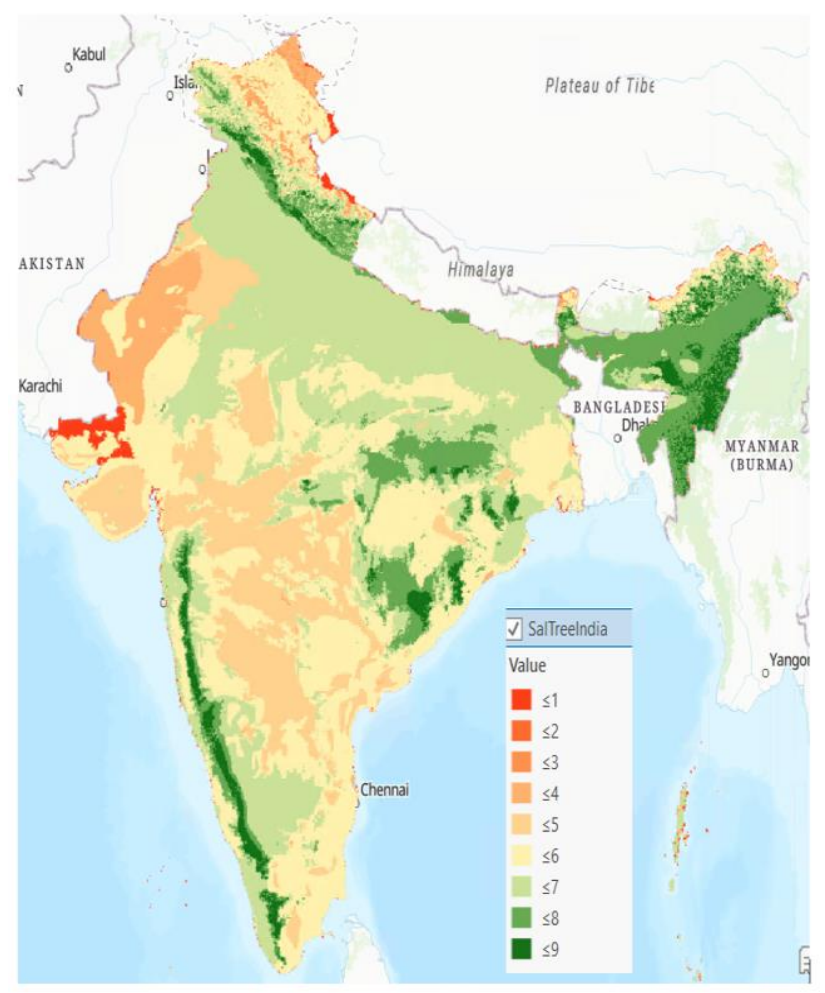

Fig. 7: Shorea robusta (Sal tree)

A plant of the tropics, where it is found at elevations up to 2000 metres. It grows best in areas where annual daytime temperatures are within the range $28-34{ }^{\circ} \mathrm{c}$.

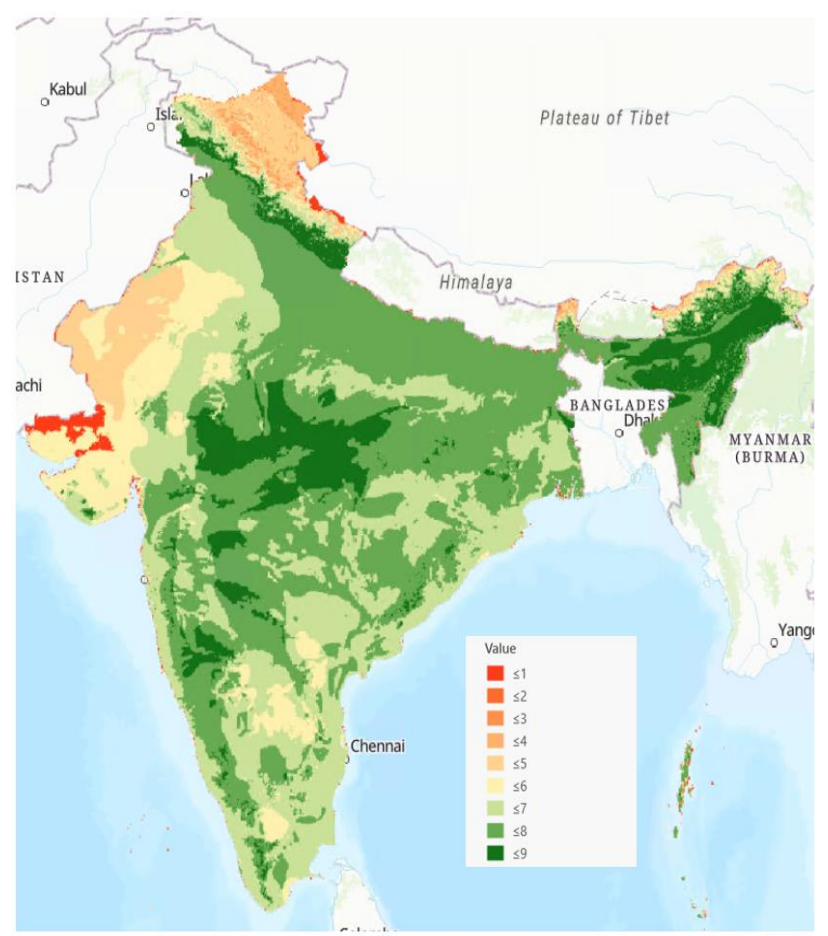

Fig. 8: Delonix regia (Gulmohar tree)

Delonix regia requires well-drained soils (clay to sandy, but it prefers sandy soils) in full sun, altitude 0-2000 m, mean annual temperature 14-26 deg C, Mean annual rainfall over $700 \mathrm{~mm}$.

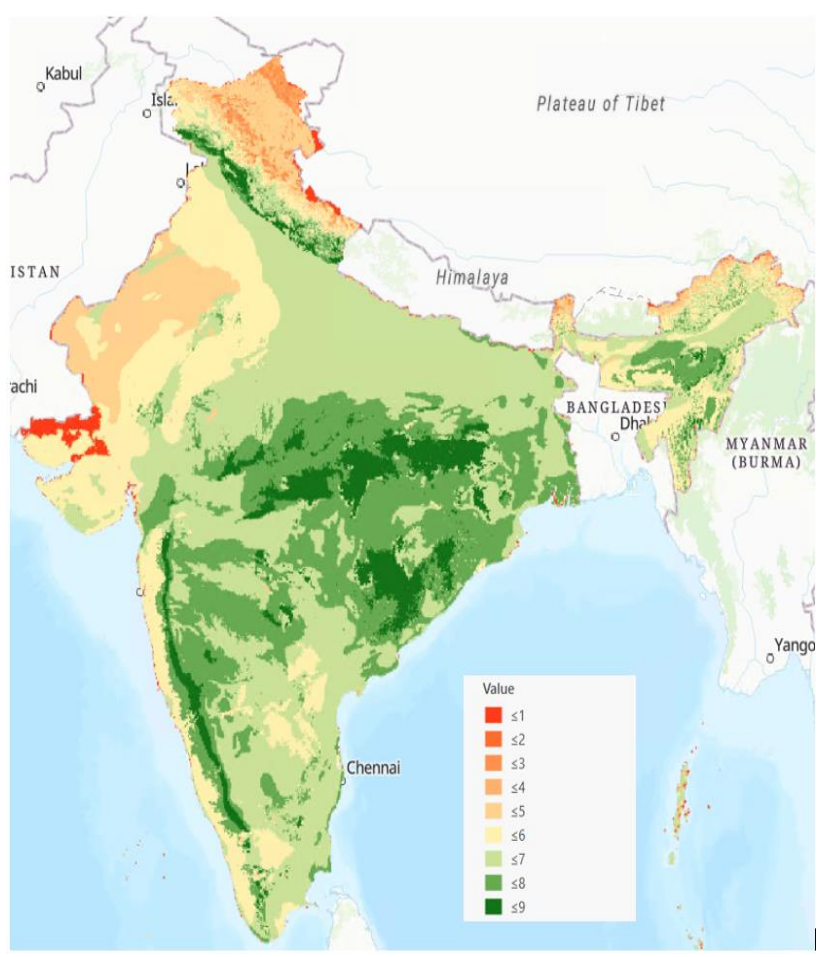

Fig. 9: Terminalia arjuna (arjuna tree)

Terminalia arjuna grows best in areas where annual daytime annual temperatures are within the range $20-33^{0}$ c. and it prefers a mean annual rainfall of 1000-1500 mm. Succeeds in any moderately fertile, well-drained soil.

\section{VALIDATION}

We have verified the satisfiability and validity of our model with the actual suitability of the tree species in the region of Thane district from Mr. Rajendra Magdum, who is assistant conservator of forests, Mumbai mangrove conservation unit.

\section{CONCLUSION}

The results certainly showed some satisfactory results for all the species we considered. However, if further developed by considering more essential parameters the system can become very consistent and accurate. The results can still be rightly doubted and various experts will have a say regarding their respective field of expertise. With more detailed information, one can certainly cover the gaps seen in the current tree suitability maps. There is no certain proven formula that can determine the exact suitability of a tree in a specific area. The formula can grow more complex if detailed input is provided. This way of producing suitability maps for afforestation purposes has not been carried out in the past in India. The method needs a lot more input data for it to be referred to as an absolutely reliable system. However, this research, for a start, shows a very good approach for creating such maps, which results in maps that are satisfactory. In our research, the suitability maps resulted in reliable spatial distribution and accuracy. Tree species have been selected very carefully (ingenuous species) offering various possibilities for afforestation throughout 
India. ${ }^{[8]}$ Such models have been created for the first time for the Indian Subcontinent and with considerable development, the system can be made robust and can be used for afforestation in any locality.

\section{CONFLICTS OF INTEREST}

The authors declare that they have no conflicts of interest.

\section{ACKNOWLEDGEMENT}

It gives us immense pleasure to express our deep and sincere gratitude to Assistant Professor Mrs Vidya Zope (Mentor) for her kind help and valuable advice during the Development of the paper. I would like to thank the ESRI team for providing us with all the necessary software requirements and giving us valuable guidance, which made this possible. We are profoundly obligated to Head of the Computer Department Dr. (Mrs.) Nupur Giri and our Principal Dr. (Mrs.) J.M. Nair for giving us this important opportunity to do the project.

\section{REFERENCES}

[1] A.Eslami, M.Roshani and M.Hassani, The Application of GIS in Selection of Suitable Species for Afforestation in Southern Forest of Caspian Sea. Research Journal of Environmental Sciences, 4: 223-236.,2010

[2] Ciprian Palaghianu, Afforestation and reforestation management in Romania -migrating to sustainability and responsibility.Proceedings of the 4th International Conference Integrated management of Environment Resources, 2017

[3] Ali Mahdavi, M. Ghasemi, Ali Akbar Jafarzadeh, Afforestation and reforestation management in Romania migrating to sustainability and responsibility, At Caspian Journal of Environmental Sciences, AUCRS(Association of Universities of Caspian Region States), 2017

[4] Nguyen Van Loi, USE OF GIS MODELLING IN ASSESSMENT OF FORESTRY LAND'S POTENTIAL IN THUA THIEN HUE PROVINCE OF CENTRAL VIETNAM, June 2008

[5] Ayhan Ateşoğlu, Remote sensing and GIS applications for suitable afforestation area selection in Turkey, JOURNAL OF THE FACULTY OF FORESTRY ISTANBUL UNIVERSITY,2015

[6] Yuling Chen, Baoguo Wu, Dong Chen and Yan Qi, Using Machine Learning to Assess Site Suitability for Afforestation with Particular Species, School of Information Science and Technology, Beijing Forestry University, Beijing 100083, China, August 2019

[7] Božin Trendafilov, Ivan Minčev, Bojan Simovski, Nikolčo Velkovski, Suitability for tree species afforestation using GIS aided landscape model in the Republic of Macedonia, Conference: International congress First Serbian Forestry Congress - Future with forests, At University of Belgrade, Faculty of Forestry, Serbia, Volume: Congress proceedings, pp.807-818. ISBN 978-86-7299-071-3, November 2010

[8] Amin Gholizadeh, Ali Bagherzadeh \& Ali Keshavarzi, Model application in evaluating land suitability for OAK and PINE forest plantations in Northeast of Iran, June 2019

\section{ABOUT THE AUTHORS}

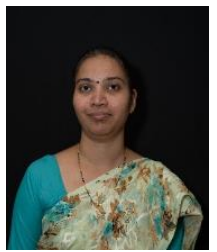

Mrs. Vidya Zope, Assistant Professor, Education Details: B.E. Computer Engineering M.E. Information Technology Publication: Mrs.Vidya Zope, Dr.(Mrs.) Nupur Giri, Personalized Ontology based Context Aware Recommender System, International Journal of Advanced Computational Engineering and Networking, ISSN: 2320-2106 Volume- 1, Issue- 6 , August 2013,pgs. 4-10. Mrs.Vidya Zope, Nilesh Thadani, Nikita Kukreja, Nisha Sajanani, Nisha Ramrakhyani B2B Management and Lead Generation International Journal of Advanced Research in Computer Science and Software engineering ISSN: 2277 128X Volume 5, Issue 10, Pgs. 500502 October 2015 Mrs. Vidya Zope, Anurag Gangal, Abhishek Talnikar, Aneesh Dalvi, Aadesh Kulkarni Analysis and prediction of football statistics using Data Mining Techniques, International Journal of Computer Applications (0975-8887) Volume 132-No.5, pgs. 8-11 December 2015

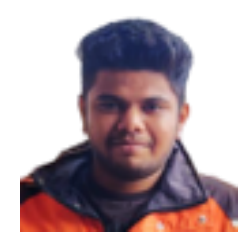

Nihar Kalsekar, Educational Details: B.E. - Computer Engineering (Final Year Student), Achievement: Grant from Microsoft Azure for AI for Earth

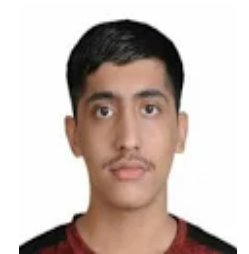

Pradyot Chhatwani, Educational Details: B.E. - Computer Engineering (Final Year Student), Achievement: Grant from Microsoft Azure for AI for Earth

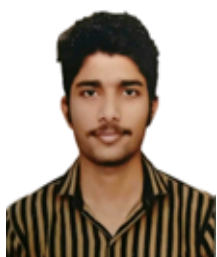

Vaibhav Mane, Educational Details: B.E. - Computer Engineering (Final Year Student), Achievement: Grant from Microsoft Azure for AI for Earth 